\title{
"LABORATORY": A PROJECT-BASED LEARNING EXAMPLE ON POWER ELECTRONICS
}

\author{
J.M. Guerrero, J. García, P. García, P. Arboleya \\ Universidad de Oviedo, Department of Electrical Engineering, \\ Gijon - Spain \\ e-mail: garciajorge@uniovi.es
}

\begin{abstract}
This paper presents the experience of applying project-based learning (PBL) on power electronics in the context of two official Master degree courses. The discussion covers both strategic and implementation topics, from the initial conception of the Master and the subject, to practical implementation issues. The final conclusions show recommendations from experience for enhancing the learning experience in coming editions of the subject that might also be useful for other academics.
\end{abstract}

Keywords - European Higher Education Area (EHEA), International Master Degree, Power Electronics Laboratory, Project-Based Learning.

\section{INTRODUCTION}

This work discusses the experiences undergone in a laboratory subject imparted at two Master courses of the University of Oviedo in Spain. The first course is the Electric Energy Conversion and Power Systems (EECPS) international Master degree [1]. The second one is the Erasmus Mundus Master Course on Sustainable Transportation and Power Systems (EMMC STEPS), an official joint degree at European Union (EU) level [2].

The EECPS Master course focuses on key electrical engineering concepts, such as power electronics, control systems, power systems, electric machines, generation systems, electrical traction systems, electrical markets and energy efficiency. That Master degree is a two year full-time official course, approved by the Spanish Government in accordance with the European Higher Education Area (EHEA) guidelines [3].

These guidelines include, among other goals, the use of a standardized unit for measuring the time devoted by the students to their academic work. This unit is the European Credit Transfer System (ECTS) [4]. In this context, one ECTS equals to 25-30 hours of student's time, which might be classroom hours (with a teacher/lecturer) or autonomous work (individual or teamwork). The final amount of hours devoted in a particular Master Course and the percentage of classroom hours vs. autonomous works are specified in the Master's Official Guide, that is an official document sent to the respective governments within the EU, in order to verify the EHEA guidelines are fulfilled. In this Master course, one ECTS equals to 25 student hours. The full Master program is 120 ECTS split in two years accounting 60 ECTS each.

The Master has been conceived as a whole from the beginning, i.e. all the subjects have been created from scratch focused to meet the Master goals. In this sense the subject "Laboratory" plays a key role in the learning objectives of the degree since it is an opportunity to put to work together concepts acquired in different subjects. The time schedule of the subject, at the end of the second semester, aims to verify the acquisition of both theoretical and practical skills of the technical topics taken during the first year.

This subject is also included at the official EMMC Sustainable Transportation and Electrical Power Systems course. The approach and contents of the degree respond to main challenges faced by the energy sector:

- To master new energy sources and their implications in power systems

- To reduce $\mathrm{CO}_{2}$ emissions by increasing energy efficiency and the share of clean energies

- To gradually incorporate electrical transportation as an alternative to vehicles using combustion engines.

Graduates successfully completing the academic programme will be awarded with a Joint Master Degree by all the Consortium universities, fully recognized in the four partner countries. The Consortium is formed by the following four EU institutions, The University of Nottingham (UK), the University of Rome /Sapienza Università di Roma (Italy), the Coimbra Institute of Engineering / Instituto Superior the Engenharia de Coimbra-ISEC (Portugal), and the coordinating institution, the University of Oviedo/ Universidad de Oviedo.

In a Joint Degree, the students move among institutions, to study different subjects of local Master degrees, within a number of scheduled tracks. Thus, they complete a pre-defined curriculum that is acknowledged by all the partners. Provided that every institution has a national accreditation of their respective courses, the resulting Joint Degree is also officinal in the four countries.

Given the importance of the subject "Laboratory" in the design of the academic development of the EECPS master, it has been also made compulsory for the EMMC STEPS Joint Degree.

The basic aim of "Laboratory" is to integrate previously acquired knowledge to develop a project having some technical challenge for the students, where they also have to learn the operation of specific instrumentation material of either a power systems or electrical transportation laboratory. Moreover, the understanding of safety issues when handling electrical equipment is a learning result of the subject, as well as achieving transversal learning skills such as autonomous learning, teamwork, etc.

In order to achieve these results, the students must certify that they have passed basic skills and competences in power electronics, power plants, electric machines and control systems and automation. This can be either accomplished at his/her incoming student profile and $\mathrm{CV}$ or, if not covered there, by passing the related subjects of the first semester. 


\section{CONTEXTUALIZATION OF THE SUBJECT "LABORATORY"}

\section{A. Higher Education in Spain}

After the Bologna Declaration (The Bologna Process - Towards the European Higher Education Area) [3], Spain adapted the Education Courses at University level by means of the Royal Decree 1393/2007 [5], It resulted in every course of every institution passing a process of accreditation by the Spanish Ministry of Education. Finally, the B. Sc. courses were settled in 240 ECTS (4 years fulltime), and the M. Sc. courses in 60 or 120 ECTS (1 or 2 years fulltime).

In this context, the EECPS Master degree is a 2 year course.

\section{B. The Electrical Energy Conversion and Power Systems (EECPS) Master Course.}

The degree is entirely taught in English language, and has two branches: one with a technological research orientation and the other devoted to economic management of electrical networks. The development of the Master contents and program has been carried out in collaboration with some of the most important companies and academic institutions worldwide (among them the four institutions that later formed the partnership of the EU joint degree). Figure 1 summarizes the program main characteristics.

Three main lines have been considered as keystones:

- Electrical Power Systems

- Electrical and Hybrid Vehicles

- Energy Efficiency and Renewable Energies

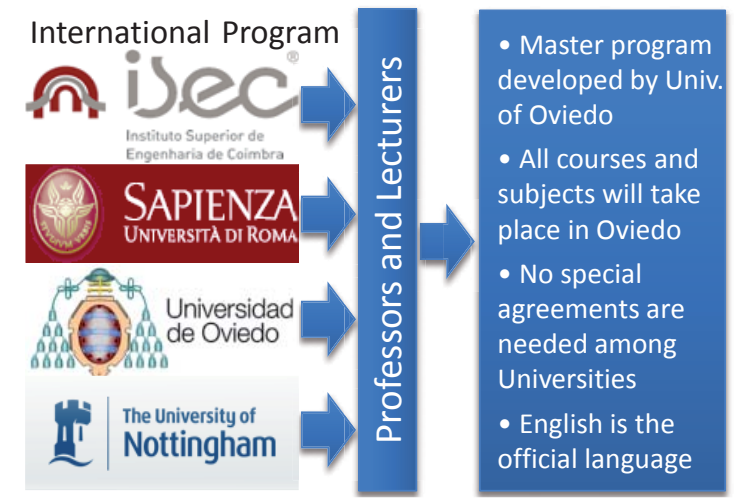

Fig. 1. International program of the EECPS Master Degree of the University of Oviedo.

The knowledge, skills, abilities and competences gained by one student after completing the Master are directly related to one of the following topics which are identified by the ANEP (Spanish Governmental Agency for Evaluation and Prospective Tasks) as strategic sectors in the Spanish National Research Program:

- Environment and Innovation in Ecosystems

- Energy

- Transport and Infrastructures

- Industrial Sectors

These competences will allow the graduates to succeed in technological, economic and management tasks, as well as in research, development and technological innovation in the main keystones.

The educational methodology, strongly focused on practical and experimental contents, guarantees a significant learning of the aforementioned skills and capabilities that nowadays are demanded by some of the most significant companies related with the Master's lines.

The main learning objectives of the Master can be summarized as follows:

- The acquisition of the knowledge and technical and management skills related to the main lines of the Master. Those skills are intended to enable the creatively tackling of the current challenges that appear in Power Systems and Renewable Energies.

- The gaining of competitive advantages to succeed in the labor market, which continuously demands increasingly qualified professionals in the disciplines related to the Master lines.

- To acquire transversal skills that allow the integration in research or management workgroups, knowing and respecting the different roles inside the group.

\section{Structure of the Master Course:}

In order to meet the set objectives and comply with the established regulations, several options were considered concerning the distribution of the compulsory credits of the Master as well as the offer of optional credits. After a thorough analysis, the following schedule was selected; the Master consists of 4 semesters distributed in two years. The basic schedule can be seen in Figure 2.

1. The first semester is intended to provide a common level of knowledge among students. It offers a set of optional courses designed to promote the homogenization among students' previous background knowledge. The teaching committee will study every application form, selecting 27 ECTS credits for every student among the optional courses. The additional 3 ECTS are dedicated to a compulsory introduction subject that approaches the student to the degree topics and methodologies.

2. The second term offers several compulsory courses for all the students. These subjects will promote the acquisition of the common skills of the Master. This term includes the subject "Laboratory".

3. The third term has been designed according to the two possible tracks: management and research. The first one is focused on the acquisition of the required competences for the management of electric energy, with a special emphasis on energy efficiency and renewable energies. The second track approaches the technology development and the industrial design established in the Master lines: "Power Systems" and "Electric/Hybrid Vehicle".

4. The last term has been designed to complete the training of the students. The courses taught in this period have a general nature and address issues related to the socio-economic impact of the technologies studied in the Master. In addition, students have to complete their 18 ECTS Master's Thesis. Besides, this term includes topics on the scientific method that allow students to start with their $\mathrm{PhD}$ studies if they wish, according to the regulations of the University of Oviedo.

\section{THE EEMC STEPS JOINT DEGREE}

On the other hand, the STEPS course presents a slightly different schedule. The course is structured in 2 academic years, with four 30 ECTS semesters for a total 120 ECTS workload. The joint degree offers 2 study tracks: Sustainable Transportation (ST) and Electrical Power Systems (EPS). 


\begin{tabular}{|c|c|}
\hline $\begin{array}{l}\text { First Semester } \\
\text { (30 ECTS) }\end{array}$ & $\begin{array}{l}\text { Outline of the Master's Program (3 ECTS) } \\
\text { Equalization Stage. Uniform skills among } \\
\text { students with different basic training. The } \\
\text { teaching committee will select } 27 \text { ECTS for } \\
\text { every student among the optional courses }\end{array}$ \\
\hline $\begin{array}{l}\text { Second } \\
\text { Semester } \\
\text { (30 ECTS) }\end{array}$ & $\begin{array}{l}\text { - Common Stage (I). Common skills of the } \\
\text { master. } 30 \text { ECTS. } \\
\text { Several compulsory courses for all } \\
\text { students. There is a subject called } \\
\text { LABORATORY (6ECTS). Students must build } \\
\text { an operational prototype of some plant } \\
\text { already analysed. }\end{array}$ \\
\hline $\begin{array}{l}\text { Third } \\
\text { Semester } \\
\text { (30 ECTS) }\end{array}$ & $\begin{array}{l}\text { - Common Stage (II). Additional } 3 \text { ECTS } \\
\text { (Simulations) } \\
\text { - Specialization Stage. Two possible tracks: } \\
\text { (Management/Professional) or (Technical } \\
\text { /Research) } \\
\text { - EE Management (27 ECTS). Includes 3ECTS } \\
\text { Internships. } \\
\text { - Technical development of EPS and HEV/EV } \\
\text { (27 ECTS). }\end{array}$ \\
\hline $\begin{array}{l}\text { Fourth } \\
\text { Semester } \\
\text { (30 ECTS) }\end{array}$ & $\begin{array}{l}\text { - Final Stage. } 12 \text { ECTS of Common subjects } \\
\text { about socioeconomic impact of EE } \\
\text { technologies. } \\
\text { - Master's Thesis: } 18 \text { ECTS. }\end{array}$ \\
\hline
\end{tabular}

Fig. 2. Basic structure of the EECPS Master Degree.

Students carry out the courses in at least three different countries, with two alternative mobility tracks: Coimbra-Nottingham-Oviedo or Rome-Nottingham-Oviedo. Students also have the opportunity of undergoing an internship in an associated university or company in Europe, America or Asia. The degree is fully taught in English. Figure 3 shows the basic mobility track of the STEPS Master Course.

The 2-week introductory course at the University of Oviedo is shared with the EECPS Master students, and it is intended to meet other colleagues as well as the University coordinators. Semester 1 is a Leveling Course to compensate for the learning gaps due to the different educational backgrounds. Students wishing to focus on ST track will rather spend this first period in Rome, while the group focusing on EPS will attend lectures in Coimbra. Semester 2 will be devoted to the study of advanced subjects both on ST and EPS in Nottingham. During Semester 3 students will complete their specialization in either of the proposed tracks in Oviedo. During this semester, all students will have the subject "laboratory" in their curriculum. Finally, in semester 4 students will carry out an internship in one of the associated Universities or world leading company, to carry out some supervised research focused in the preparation of the Master thesis.

\section{THE SUBJECT: "LABORATORY"}

The subject is intended to develop and build a functional experimental prototype, based on the theoretical knowledge acquired during the first two semesters. This Project-Based Learning strategy has been successfully applied in power electronics related topics [6][8]. Generally speaking, the work done in this subject will serve as a starting point for the Master's Thesis.

The subject is a 6 ECTS subject, accounting for 150 hours of student's work, including autonomous work. The percentage of classroom hours is $50 \%$, thus each student must devote 75 class hours to this subject. As the Master degree has been scheduled in sessions of 1.5 hours each, a total amount of 50 sessions is assigned for this subject in the timetable.

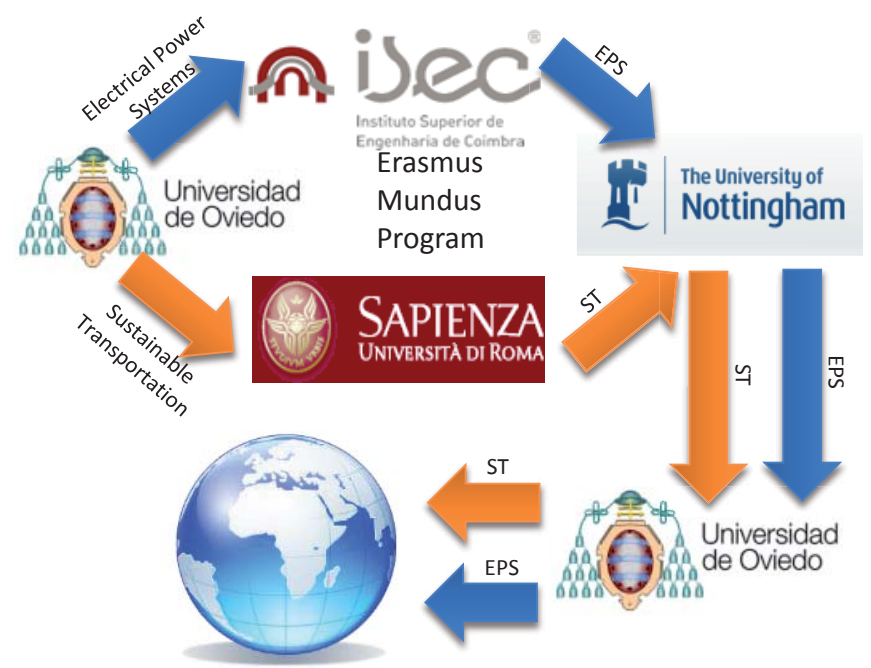

Fig. 3. Mobility track scheme of the EMMC STEPS

The learning outcomes of this subject, in terms of knowledge, skills and competences are the following:

- To deal with the specific instrumentation material of a power systems laboratory. Given the characteristics of this laboratory, safety issues when handling such equipment will be emphasized.

- To integrate previous knowledge to develop a project of some importance.

- Develop learning skills and independent work.

- Presentation of a report/project in public.

The key here is the integration of the previous knowledge acquired in the Master degree. Table I shows some of the key learning results of some of the previous subjects that are specifically emphasized during the subject "Laboratory".

As it can be seen from table I, there are a lot of concepts that the students should know at theoretical and practice level. However, after two editions of the Master degree, it is clear that although the theoretical knowledge is usually acquired, the practical skills are harder to gain.

The syllabus and schedule of "Laboratory" is focused on gaining these practical skills. The following information is obtained from the learning guide of the subject [9], and summarizes the contents as well as the development of the subject itself:

1. Projects presentation and assignment.

2. Power systems laboratory safety rules.

a. Laboratory safety rules.

b. Laboratory equipment safety guide.

3. Laboratory Seminars

a. Drivers for controlled switches

b. Design of Inductors

c. Advanced programming of microcontrollers from simulation tools

d. Design of printed circuit boards (PCBs)

4. Project development.

a. Supporting calculations (some of them could have been previously done in a previous second semester subject). 
TABLE I

Main learning results of the previous subjects

Subject: "Hybrid Control Systems"

- Understanding of the fundamentals of digital control systems.

- Implementation of control systems on digital systems

\section{Subject: "Electronic CAD"}

- Knowledge of the design process and technologies involved in the practical realization of electronic circuits.

- Manage various electronic CAD environments (simulation, board design, component creation, etc.).

- Design and develop a prototype electronic circuit from its basic concept (electrical circuit diagram) to the physical realization of the board itself.

- Integrating different electronic CAD tools

\section{Subject "Power Electronic Circuits"}

- Application of the most appropriate techniques for power electronic conversion and control, basic topologies and devices.

- Integrate knowledge previously seen by selecting the appropriate topology for a given power application.

- Manage specific software simulation of electronic circuits and specific laboratory equipment.

- Basic modeling of power loads and power supplies to carry out simulations of a full power electronics system

Subject "Industrial Electronics in Renewable Energy Generation Systems"

- Understanding and ability to apply the main particularities and specific techniques of electronic circuits used in Renewable Energy (RE) power generation systems

- Analysis and design of complex power electronics systems.

- Comparison and justified selection of devices and power electronic circuits appropriate for a given type of RE generator.

- To know the optimization margins of power generation system, aiming for an enhanced performance.

\section{Subject "Control and Monitoring in Renew. Generation}

Systems"

- To know and to compare different power converter topologies applied to both power systems and electric and hybrid vehicles.

- To design power converters and control systems for application in wind generation, photovoltaic systems and electric traction.

- To know and select the communication and telemetry system best suited for a particular energy-generating structure.

- Practical implementation of control circuits used in power generation systems for renewable energy sources.

- To integrate communications systems in power systems.

- To integrate monitoring systems in power systems.

Subject "Analysis and simulation of electric power systems"

- To know the basic properties of simulation software for PS.

- To characterize and model the electrical components of PS.

- To select the best numerical methods of solving transient electromagnetic, knowing the limitations of the solution.

- System's dynamic modeling for full the system simulation

- To analyze the different strategies of grid connection.

- Extrapolating the results of the simulation to actual implementation, understanding the implicit limitations a. Simulations (some of them could have been done in a previous second semester subject).

b. Sizing of components, purchasing list (approval needed form the advisor).

c. Hardware: design, development and construction (approval needed form the advisor).

d. Follow-up meetings.

5. Project assessment.

a. Submission of the project documentation.

b. Oral presentation of the final report.

c. Demonstration of the prototype.

\section{THE PROJECTS}

At the beginning of the semester, the different projects are presented in a common session to the students. The specification of the projects include the main objectives, the advisor/s, the number of students per project ( 2 as regular basis), the recommended specific skills needed (complementary profiles if possible), as well as the main schedule of the project development.

The main objectives vary from construction of a full operating prototype of a given power electronics circuit, to a specific design of a subsystem (e.g. gate driver for HV systems), or a re-design and optimization of a given equipment.

The incoming profile to the master of the students can be quite different, depending on their previous background. Although the first levelling semester aims to decrease these differences, some knowledge gaps remain between the students. For instance, some students are pure electrical systems engineers, with a very strong background in power systems and electric machines, but with lack of electronics, control systems or communications knowledge. On the other hand, electronics and automation engineers, have some knowledge gaps on electrical systems. Also, telecommunications engineers or mechanic engineers have a different knowledge background.

The idea of the subject is to use these knowledge differences, rather than obviating them. Thus, the idea is to merge 2 or 3 students, depending on the project entity, but with a different profile. Thus, the students will experience team work from a new point of view, not only among people with the same background (that it is usually their previous experience), but among people with different and complementary background and skills.

Based on the academic committee of the subject and in the student's preferences, the projects are assigned.

Some examples of the projects proposed can be seen in the following sections:

\section{A. Project \#1: Design and Construction of a Boost Converter for Maximum Power Point Tracking for a Photovoltaic Panel.}

1) Introduction - This document provides instructions for a laboratory project to build a functional DC-DC Boost converter for PV generation. The resulting system must achieve MPPT from a voltage source or from a Photovoltaic Panel. The design must include the creation of the PCB, the sizing and selection of components, drivers, voltage and current sensors, passive elements and connectors, as well as defining the interface with the control stage.

2) Project Tasks - The project can be divided into several subcircuits:

- The DC to DC boost converter design and construction. 
- Specifications: $100 \mathrm{~V}_{\mathrm{DC}}$ output voltage bus, up to $50 \mathrm{~V}_{\mathrm{DC}}$ input, Max power $50 \mathrm{~W}$.

- Size of the necessary components

- Design of the inductor

- The MPPT Control

- Design of the control loop strategy (nested loops approach, single loop approach, etc.). Design of the controller.

- Control Algorithm to obtain the MPPT. The input source is a Thevenin circuit, formed by a voltage source of $30 \mathrm{~V}$ DC and a series resistor of $30 \mathrm{Ohm}$.

- Power-Control Interface

- Signals to measure. Design of current/voltage acquisition circuits. Measure of currents and voltages

- Programming of the ADC.

- Control-Power interface

- Obtaining the PWM pulses.

- Driving pulses from the DSP to the Power Switch.

3) Procedure and Methodology - The procedure will be the following:

- Design and simulation of the power stage, including the design of the control loops and the MPPT strategy.

- Size of all the components. Components selection, Construction of the inductor.

- Drawing of the Schematics, Construction of the PCB, mounting of components.

- Programming of the DSP for providing the control loops and the MPPT strategy.

- Experimentation and validation of the prototype. Design of experiments.

- Summary of the work done. Report.

\section{B. Project \#2: Open-loop speed control of induction motor AC} drives

1) Introduction - The main goal is to control the rotational speed of an induction motor powered by a three-phase inverter in openloop. The commercial power stage includes a rectifier, a dc-link, a three-leg inverter, drivers to trigger the IGBT's, current sensors and DC-link voltage sensors.

The project must address:

- The development (design and construction) of an interface PCB to adapt the signal levels between a Texas Instruments experimenter kit, which will be used for control implementation, and the power stack. This card also has to handle the charge of the DC-link.

- The development (design and coding) of a control program to control the speed of the induction motor based on a reference given by a potentiometer.

\section{2) Project Tasks:}

- Signal conditioning card:

- Will be able to adapt the PWM coming from the DSP to the power stack and also the signal conditioning from the sensors at the power stack to the DSP.

- Will have all the switches and pushbuttons needed for reset and for security purposes, as well as all the fault management of the system.

- Control software:

- The control program must read the current and dc-link signals and be able to show them (scaled) using the DA
(PWM+filter) channels of the DSP. The user can select what signals are to be seen at any time.

- The program has to deliver the PWM signals to fire the inverter IGBTs following a $\mathrm{V} / \mathrm{Hz}$ strategy. The speed (frequency) command will come from a potentiometer.

- Implementation of protections

- Advanced task:

- Implement a stationary frame current controller for the induction motor. The controller must be able to correctly control the current both in the d-and q-axis.

- Rotate the current vector with a frequency given by a potentiometer.

3) Procedure and Methodology - The interface board design and the control software program must be developed in parallel.

- Interface board:

- Make a draft design of the interface board. Make a fast PSIM (or other software) simulation. Size basic power components.

- Make a detailed schematic of your circuit taken into account the precise characteristics of the selected components.

- Draw the PCB.

- Build the card.

- Test it unconnected. Use the signal generator to generate input signals.

- Control software:

- Make a simple program driven by an interrupt to test the hardware involved in this project.

- Obtain the signals from the ADCs.

- Produce 3 PWM complementary signals with fixed duties. Check the dead time generation.

- Develop the V/Hz algorithm. Change the PWM duties according to it.

- Test the output signals.

- Common

- Test the DSP connection. Use the signal generator to generate input signals in the power stack side.

- Test the full system.

- Summary of the work done. Report.

\section{Current control of a three phase LC load connected to a virtual} grid

1) Introduction - The goal of this project is the current control in a LC load connected to a three phase inverter. The commercial power stage includes a three phase rectifier, DC link and the inverter itself to which the load is controlled. The virtual grid will be emulated from the readings of two voltage sensors connected to the rectifier side of the power stage. The current control must be able to inject the current with an arbitrary power factor with respect to the virtual grid using a vector control approach.

- The development (design and construction) of an interface PCB to adapt the signal levels between a given microcontroller, which will be used for control implementation, and the power stack. This card also has to handle the charge of the DC-link.

- The development (design and coding) of a control program to control the current at the LC load with an arbitrary power factor.

2) Project Tasks:

- Signal conditioning card: 
- Will be able to adapt the PWM coming from the DSP to the power stack and also the signal conditioning from the sensors at the power stack to the DSP.

- Will have all the switches and pushbuttons needed for reset and for security purposes, as well as all the fault management of the system.

- Control software:

- The code has to implement a vector control strategy which includes synchronization with the virtual grid and current injection in the LC load which an arbitrary power factor.

- Synchronization will be done by an arc tangent function. The magnitude and phase (power factor) of the injected current must be changed in real time using a Timer Interrupt Service Routine.

- The program has to deliver the PWM signals to fire the inverter IGBTs.

- There will exist the possibility to store one signals (measured or commanded) in the available memory of the DSP.

- Advanced task:

- Remotely send the commands from a PC using the serial interface.

- To test different synchronization methods with the virtual grid (PLL).

3) Recommended steps - The recommended steps are the same than the ones at project B

\section{THE LAB ROOMS}

For proper development of the projects, there are two complete dedicated laboratory rooms suited for the students. At the Microcontrollers Lab, there is a set of 10 complete stations, each one with a setup with full development tools for debugging and programming microcontrollers (TMS320F28335 from Texas Instruments), along with development kits for motor control, PFC, use of peripherals, as well as all the required instruments for programming and measuring (computer, oscilloscope, voltage differential probe and current probes, pulse generator, DC power supply). Figure 4 shows some photographs of this dedicated room.

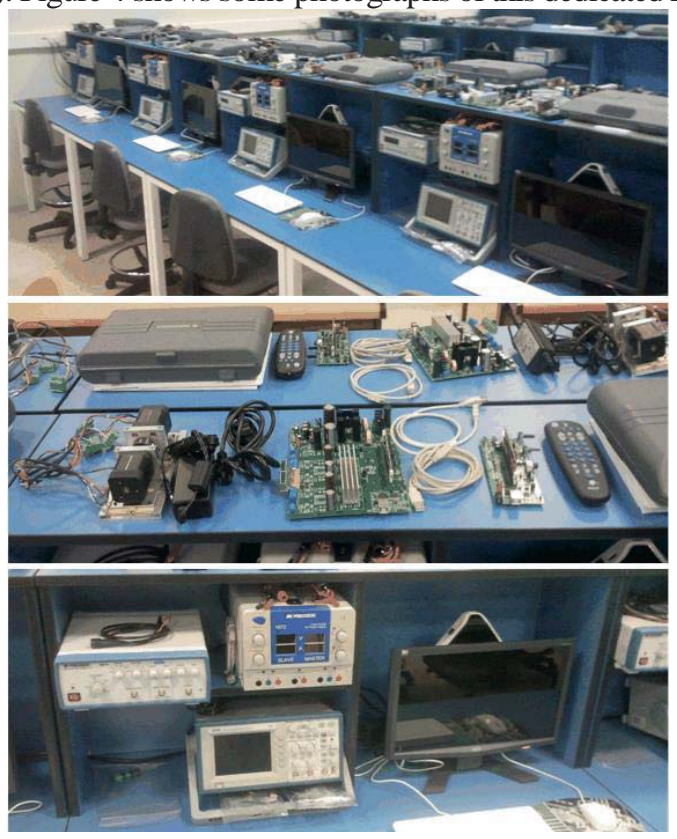

Fig. 4. Microcontrollers Lab of the EECPS \& EMMC STEPS
The second Lab is dedicated to power systems. A Motor + Generator setup, based on 1.5kW M2AA 090L-4 motors from ABB, is available at all the stations (Figure 5). The configuration of the motors and of the ACS355-03E-04A1-4 frequency controllers (ABB) allows for complete control of the system, emulation of generator behavior, speed or torque control of the motor, etc. Also, an $80 \mathrm{kVA}$ diesel generator is connected to all the lab stations, in order to act as a weak grid for testing. This last feature is useful when assessing the development of power electronics and control designs for grid synchronization in order to deliver energy the grid. Also, uncontrolled three-phase inverters MTL-CBI0010N12IXFA from Rectificadores Guash are available for the students.

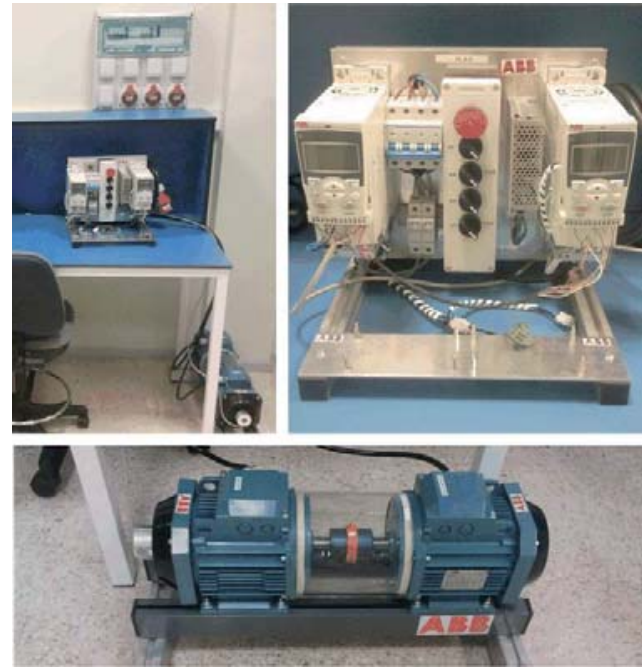

Fig. 5. Power Lab of the EECPS \& EMMC STEPS

\section{ASSESMENT OF THE STUDENTS LEARNING:}

In accordance with the regulations for the accreditation of the master degree, all the subjects must be evaluated in accordance with a fixed table. The weights of the percentages can be tuned for each subject. The percentages of the final qualification of the different evaluation systems used in "Laboratory" are shown in table II.

TABLE II

Assessment table for the subject

\begin{tabular}{lc}
\hline Evaluation systems & $\begin{array}{l}\text { Proposed } \\
\text { percentage }\end{array}$ \\
\hline $\begin{array}{l}\text { Written tests (objective tests, short answer tests and / } \\
\text { or test development) }\end{array}$ & $15 \%$ \\
\hline $\begin{array}{l}\text { Oral tests (individual, group, presentation of } \\
\text { topics/projects, etc.) }\end{array}$ & $15 \%$ \\
\hline Works or projects & $50 \%$ \\
\hline Observation Techniques (logs, checklists, etc.) & $10 \%$ \\
\hline Real / Simulated Task Performance Tests & $10 \%$ \\
\hline
\end{tabular}

Translating this information to the particular requirements of the subject yields to the following assessment information:

- The $50 \%$ of the students' grade comes from the assessment of the proposed projects.

- Another $10 \%$ will come from the simulations developed by the student, considered as a simulated task performance test.

- Another $15 \%$ comes from an individual written test, which will be done at the end of the semester. This test will be comprehensive covering all topics discussed. 
- A $15 \%$ will come from oral presentation of the developed project by the students.

- Completion of the above tasks is mandatory to pass the course.

Finally, the $10 \%$ left comes from the assistance to the class hours (a minimum of $50 \%$ is required).

\section{EXPERIENCE}

The development of the experience must be discussed from different points of view.

The first of these points of view would be the student's one. After several quality meetings, students tend to state that they are satisfied with the experience. Although they find a much higher workload than initially expected, their final impression is positive, stating that they are able to apply theoretical knowledge into real physical power electronics systems. Also, they also find positive that at this subject they find the first time along the master course where they actually know the meaning of teamwork. Instead of simply dividing workpackages from a given task, these projects mean real interaction between people, with issues of synchronization, load leveling, leadership, etc.

From the point of view of teachers, the benefits clearly overcome the drawbacks. It is also a higher workload for teachers. However, the final students' achievements actually developing power electronics hardware is worth the efforts. In addition, it is a very useful platform to detect lacks in the teaching of some topics at previous subjects. Hence, this subject is also understood as a tool for gathering information in order to carry out a feedback in the teaching system of the Master degree. The teachers also state that even though the students are intrinsically highly motivated to apply to the Master Course (the key topics of the master are quite specific, it is a two years master, and unlike other alternatives the Master is not a mean of obtaining regulated competences, as for civil engineer or medicine degrees), this subject is seen as one of the most fruitful and motivating of the full Master Course.

\section{CONCLUSION}

After the experience of the scheduling, programming, teaching and assessment of the subject "Laboratory", some useful conclusions can be derived. These conclusions have been successively implemented in the program methodology and in the learning guides, in a continuous improvement of the teaching.

- The scheduling of the subject is at the end of the semester, but the projects must be assigned as soon as possible. This allows the students to organize themselves, and also helps to identify the key concepts.

- Basic seminars are scheduled also at the beginning of the classes. In particular, safety issues when handling such equipment must be emphasized, including procedures to following case of accidents.

- The work teams selected must be as heterogeneous as possible, in order to seek for synergies between different skills coming from different incoming profiles.

- Documentations for defining the task must be as realistic as possible. All the information must be accessible to the students from the beginning.

- The advance and development of the teams must be monitored continuously, e.g. in a weekly basis. Also, advisors must share information of the progress of the groups, in order to early detect delays.

- Each project must be designed thoroughly, particularly in terms of expected length of the tasks (i.e. how many lab sessions per task). The number of sessions involved in each of the project tasks must be specified, and progress interviews must be fixed from the beginning. This helps both the students to develop their work and the teachers to refine the design of future projects.

- The opinions of the students are critical for a good evaluation of the teaching procedure. Their suggestions and ideas, and the problems encountered during the subject must be analyzed.

\section{ACKNOWLEDGEMENT}

The authors wish to thank the EACEA for funding this work as a part of the Erasmus Mundus Master Course in Sustainable Transportation and Power Systems, EMMC-STEPS, under grant \# 520188-1-2011-1-ES-ERA MUNDUS-EMMC.

\section{REFERENCES}

[1] Official Webpage of the EECPS Master Course: http://mastereecps.uniovi.es (last access: 07/18/2014)

[2] Official Webpage of the EMMC STEPS Master Course: http://www.emmcsteps.eu (last access: 06/16/2014)

[3] "The Bologna Process - Towards the European Higher Education Area”, EU, http://www.ehea.info/Uploads/Declarations/BOLOGNA DE CLARATION1.pdf/ (last access: 07/18/2014)

[4] Webpage of the European Comission for Education and Training: http://ec.europa.eu/education/lifelong-learningpolicy/ects en.htm (last access: 07/18/2014)

[5] "Ordaining the Official University Education" Official Spanish Bulletin, RD 1393/2007, BOE no. 260/2007, Tuesday, October $30^{\text {th }}, \mathrm{pp} 44037$

[6] D.G. Lamar, P.F. Miaja, M. Arias, A. Rodriguez, M. Rodriguez, J. Sebastian, "A project-based learning approach to teaching power electronics: Difficulties in the application of ProjectBased Learning in a subject of Switching-Mode Power Supplies," Education Engineering (EDUCON), 2010 IEEE , vol., no., pp.717,722, 14-16 April 2010 doi: 10.1109/EDUCON.2010.5492509

[7] R.H. Chu; D.C. Lu, S. Sathiakumar, "Project-Based Lab Teaching for Power Electronics and Drives," IEEE Transactions on Education, vol.51, no.1, pp.108,113, Feb. 2008 doi: 10.1109/TE.2007.906607

[8] P. Bauer,, J.W. Kolar, "Teaching Power Electronics in the 21st Century", EPE Journal · Vol. $13 \cdot$ no. $4 \cdot$ November 2003

[9] Official learning guide of the subject "Laboratory": http://sies.uniovi.es/ofe-podjsf/web/asignatura/infoAsignatura.faces (last access: 07/18/2014)

\section{BIOGRAPHIES}

Juan Manuel Guerrero was born in Gijon, Spain in 1973. He received the M.E. degree in industrial engineering and the $\mathrm{Ph} . \mathrm{D}$. degree in electrical and electronic engineering from the 
University of Oviedo, Gijón, Spain, in 1998 and 2003, respectively.

Since 1999, he has occupied different teaching and research positions with the Department of Electrical, Computer, and Systems Engineering, University of Oviedo, where he is currently an Associate Professor. From February to October 2002, he was a Visiting Scholar at the University of Wisconsin, Madison, WI, USA. From June to December 2007, he was a Visiting Professor at Tennessee Technological University, Cookeville, TN, USA. His research interests include power converters' control, wind energy applications and sensorless control.

Dr. Guerrero is member of IEEE. He was the recipient of an award from the College of Industrial Engineers of Asturias and León, Spain, for his M.E. thesis in 1999, the University of Oviedo Outstanding Ph.D. Thesis Award in 2004 and three IEEE Industry Applications Society Conference prize paper awards. He has been coauthor of more than 20 journal papers and more than 40 conference papers.

Jorge Garcia was born in Madrid, Spain, in 1975. He received the M.Sc. and $\mathrm{PhD}$. degrees in electrical engineering from the University of Oviedo, Asturias, Spain, in 2000 and 2003, respectively.

In December 1999, he joined the Electrical and Electronic Engineering Department of the University of Oviedo, where he is currently an Associate Professor. He has been visiting professor in the Universidade Federal de Santa Maria, RS, Brazil in 2012, and in Università di Roma-La Sapienza, in 2013. His research interests include power electronic converters (power topologies, control schemes and modelling), digital control, integration of stages, magnetic components, Energy storage systems, lighting electronics and industrial applications.

Dr. Garcia is co-author of more than 30 journal papers and more than 60 international conference papers in power and industrial electronics. He is Senior Member of the IEEE since 2011.

Pablo García was born in Luanco, Asturias, Spain the 10th of July 1975. He received the M.S. and PhD degrees in electrical engineering and control for the University of Oviedo, Gijon, Spain in 2001 and 2006 respectively.

$\mathrm{He}$ is currently an associate professor with the Department of Electrical, Computer and Systems Engineering, University of Oviedo. For the period of 2002-2006 he has been awarded a fellowship of the Personnel Research Training Program funded by the Spanish Ministry of Education. In 2004 he was a visitor Scholar at the University of Madison-Wisconsin at the Wisconsin Electric Machines and Power Electronics Consortium (WEMPEC). His research interest includes AC drives, sensorless control, AC machines diagnostics, electrical energy conversion and storage, magnetics bearings and signal processing.

Dr. García is IEEE member for 13 years. He belongs to the Industry Applications Society, Power Electronics Society, Industrial Electronics Society and IEEE Young Professionals. He has been awarded with three Industrial Drives Committee prizes and one IEEE Transactions on Industry Applications.
Pablo Arboleya, Oviedo 1977 Received the M.Eng. and Ph.D. (with distinction) degrees from the University of Oviedo, Gijón, Spain, in 2002 and 2005, respectively, both in electrical engineering.

$\mathrm{He}$ is Senior member of the IEEE Power and Energy Society since 2013 and was a recipient of the University of Oviedo Outstanding Ph.D. Thesis Award in 2008. Nowadays, he works as an Associate Professor in the Department of Electrical Engineering at the University of Oviedo (with tenure since 2010). In 2013, he was a visitor professor at the University of Rome (La Sapienza). He worked several years in the field of electrical machines design and faults detection, participating in more than 20 research projects with companies like ABB, Arcelor, EdP, REE, Hidrocantabrico, CAF. Presently his main research interests are focused in the electrical networks modeling and analysis techniques, he worked with conventional transmission network analysis but he also developed models for DC traction networks and special distribution networks like microgrids with embedded distributed generators.

Dr. Arboleya is Senior member of the IEEE Power and Energy Society since 2013 and he is reviewer of IEEE transactions like IEEE transactions on Power Systems, IEEE transactions in Power Delivery, IEEE transactions on Smart Grid and IEEE transactions on Industrial Applications. 